\title{
Intravaginal Pulsed Contractile Radiofrequency for Stress Urinary Incontinence Treatment; A Safety Study
}

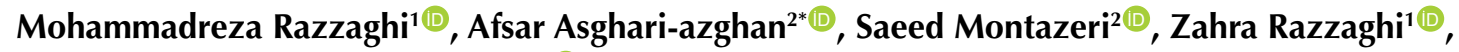 \\ Mohammad Mohsen Mazloomfard ${ }^{1}$, Reza Vafaee $^{3}$ \\ ${ }^{1}$ Laser Application in Medical Sciences Research Center, Shahid Beheshti University of Medical Sciences, Tehran, \\ Iran \\ ${ }^{2}$ Urology Department, Shohada-e-Tajrish Hospital, Shahid Beheshti University of Medical Sciences, Tehran, Iran \\ ${ }^{3}$ Proteomics Research Center, Shahid Beheshti University of Medical Sciences, Tehran, Iran
}

\author{
*Correspondence to \\ Afsar Asghari-azghan, Urology \\ Department, Shohada-e- \\ Tajrish Hospital, Shahid \\ Beheshti University of \\ Medical Sciences, Tehran, \\ Iran. Tel: +98919158648, \\ Fax: +98 2122712234, Email: \\ drafsarasghary@gmail.com
}

Received: August 26, 2020 Accepted: April 17, 2021 Published online October 9 2021

\begin{abstract}
Introduction: Radiofrequency (RF)-based stress urinary incontinence (SUI) treatment, which has quickly attracted attention, is administered in an office setting. This pilot-safety study assessed the efficacy of transvaginal RF treatment in the quality of life (QOL) and frequency of incontinence episodes in women with SUI.

Methods: Twenty-eight women suffering from SUI were treated with an intravaginal quadric applicator while a grounding pad was attached in front of their pubes. The first phase is thermic which will heat up the vaginal wall up to $40^{\circ} \mathrm{C}$ for 10 minutes. The second step is contraction to stimulate an aerobic exercise of pelvic floor muscles for 20 minutes (pulsed contractile RF at 20-40 watts and $1000-300 \mathrm{kHz}$ with a modulation of 1 to $300 \mathrm{~Hz}$ for muscle exercise). It was scheduled for one session per week for 3 sessions. Patients had follow-up visits before and 1, 6 and 12 months following the treatment for one-day voiding diary, Persian version of urinary incontinence QOL questionnaire (I-QOL), Q-tip test, 24 hours-pad test and daily incontinence episodes' number.

Results: The patients' mean age, duration of incontinence and median vesical leak point pressure were $41.6 \pm 9.6$ years, $5.48 \pm 6.84$ years and $140 \mathrm{~cm} \mathrm{H} \mathrm{H}_{2} \mathrm{O}$ respectively. Significant changes were observed in the mean I-QOL total score and the pad test. Also, a notable reduction was observed in the number of daily leakage episodes and the Q-tip test at any follow-up visit $(P=0.001)$.

Conclusion: Preliminary results suggest that transvaginal RF is a convenient method of SUI treatment. Significant changes were observed in the mean I-QOL total score and the pad test. Also, a notable reduction was observed in the number of daily leakage episodes.
\end{abstract}

Keywords: Urinary stress incontinence; Pulsed radiofrequency treatments; Incontinence pad

\section{Introduction}

In the adult female population, stress urinary incontinence (SUI) prevalence varies from $4 \%$ to $35 \%$ in different studies. ${ }^{1-3}$ Due to considerable negative impacts on relational and psychological well-being and also social and personal consequences, SUI results in significant impacts on the health condition of patients. ${ }^{4}$ This makes the constant search for an ideal treatment a just cause.

In the course of the last decade, establishing novel minimally invasive surgical techniques for SUI has attracted much attention. ${ }^{5}$ Less invasive methods usually lead to a shorter postoperative recovery time and hospital stay, and they may also cause less surgical complications rates. ${ }^{6,7}$
SUI is a multifactorial condition. It may be due to the inadequate suspension of the anterior vaginal wall and pelvic floor support and/or probable changes in the closure mechanism of the urethra. ${ }^{8}$ Moreover, histological evaluations demonstrated that in case of sphincter dysfunction and/or loss of urethral support, there is a decrease in the collagen percentage of the urethral walls, ${ }^{8}$ thus turning therapy with radiofrequency (RF) into a viable option. ${ }^{9}$

RF was first proposed as a treatment option for SUI in 2002 and its potential to be performed in an office setting with oral sedatives or local anesthetics quickly attracted attention from surgeons worldwide. ${ }^{10}$ RF treatment is a well-known therapeutic modality that has been

Please cite this article as follows: Razzaghi M, Asghari-azghan A, Montazeri S, Razzaghi Z, Mazloomfard MM, Vafaee R. Intravaginal pulsed contractile radiofrequency for stress urinary incontinence treatment; a safety study. I Lasers Med Sci. 2021;12:e56. doi:10.34172/ jlms.2021.56. 
successfully utilized by many different medical disciplines to treat a variety of conditions. ${ }^{2,11}$

$\mathrm{RF}$ electrothermal energy is considered to be an effective modality to heat connective tissue, thus causing shrinkage of the treated tissue in the process. ${ }^{12} \mathrm{RF}$ collagen denaturation focuses on reducing regional dynamic tissue compliance without reducing luminal caliber or creating strictures, which results in a functional change rather than an anatomic change. ${ }^{4}$ Concerning its effectiveness, available studies showed conflicting results. ${ }^{6,13,14}$

This pilot study was carried out to assess the efficacy and safety of transvaginal RF treatment in patients' quality of life (QOL) and frequency of incontinence episodes in women with SUI.

\section{Materials and Methods Participants}

Twenty-eight women suffering from SUI and bladder outlet hypermobility (based on complete medical history, physical examination, pad test and Q-tip test) enrolled in the study using convenience sampling between May 2017 and September 2019 at Shohada-e-Tajrish hospital, Tehran, Iran.

\section{Inclusion and Exclusion Criteria}

Eligible criteria were: the age of 18 years or more, absence of urgency symptoms (clinical complaint plus voiding diary per three days), and also more than $1 \mathrm{~g}$ urinary leakage in a 1-hour pad test. Furthermore, a washout period of 60 days for any known drugs altering urethral or bladder function was mandatory.

Women were excluded if they had a clinical history of mixed or urge incontinence, baseline leak point pressure of $60 \mathrm{~cm} \mathrm{H} 2 \mathrm{O}$ or less, post-void residual volume of 50 $\mathrm{mL}$ or more, urinary tract infection, grade III uterine and/ or vaginal prolapse, neurological chronic degenerative diseases, previous bladder or pelvic irradiation, or if they had a previous history of SUI treatment (physical or surgical therapy). Pregnant women were also excluded from the study.

\section{Procedure Description}

All women were treated with an intravaginal quadric RF applicator (Higgs CRF Generator device). The procedure was carried out while the undressed patient was in the lithotomy position. It did not require local anesthesia or sedation. The patients emptied their bladder prior to the procedure. The lubricated applicator was passed transvaginally.

The first phase was thermic RF which heated up the vaginal wall up to $40^{\circ} \mathrm{C}$ for 10 minutes. After completing this step without removing the vaginal applicator, we applied the next step. The second step was contractile RF to simulate an aerobic exercise of mucosal and pelvic floor muscles for 20 minutes.
The treatment was performed with pulsed contractile $\mathrm{RF}$ at $20-40 \mathrm{~W}$ and $1000-300 \mathrm{kHz}$ with 1 to $300 \mathrm{~Hz}$ massage frequency for muscle exercise.

One session per week for a total of 3 sessions lasting for 30 minutes each was performed. In the recovery room, the patients marked the number on the visual analog scale (VAS) which was best related to their level of pain at the time. The VAS ranges from 0 (representing no pain) to 10 (representing extreme pain). All subjects returned home the same day. Mean recovery time was $71 \pm 42$ min.utes

\section{Assessment}

The patients underwent follow-up visits before the treatment (baseline) and also at 1 month, 6 months, as well as 12 months after treatment by Persian version urinary incontinence quality of life questionnaire (I-QOL), oneday voiding diary (estimation of average daily leakage episodes based on continence diary), ${ }^{15} \mathrm{Q}$-tip test (Mobility degree of the urethra which was assessed by Q-tip test and considered to be present at a Q-tip excursion more than $30^{\circ}$ with Valsalva maneuver.), daily incontinence episodes frequency (72-hour voiding diary at each follow-up visit) and 24 hours pad test.

The I-QOL is comprised of 22 questions which evaluate the impact of urinary incontinence on patients' QOL. The patients choose 1 of 5 responses defined to each question on this rapidly completed, self-administered, validated instrument (Each question meets a score ranging from 1 to 5 points). Finally, the total sum is converted to a hundred-point total score and three 100 -point subscale scores. ${ }^{16,17}$

Using a Likert scale satisfaction questionnaire, the level of the patients' satisfaction after the treatment was evaluated according to a 5-point system which categorized the response to the treatment as follows: very satisfied, satisfied, neutral, dissatisfied and very dissatisfied.

Safety was evaluated through the elicitation of all adverse effects regardless of duration, frequency and symptom significance.

\section{Statistic}

Patients served as their own controls, which resulted in dependent samples. Categorical variables such as the level of patients' satisfaction are expressed as percentages $-n$ (\%) and frequencies. Continuous variables are expressed as mean \pm standard deviation. All data were compared with the chi-square test and paired-samples $t$ test. A $P$ value less than 0.05 was considered to be statistically significant.

\section{Results}

All patients completed the 3 sessions. The mean age of the patients was $41.6 \pm 9.6$ years (in the range of 31-68). The mean pregnancy rates and deliveries were $3.89 \pm 1.25$ and $3.1 \pm 1.12$ respectively. Also, the mean body mass 
index was $28.69 \pm 6.85 \mathrm{~kg} / \mathrm{m}^{2}\left(22-38 \mathrm{~kg} / \mathrm{m}^{2}\right)$. The mean duration for urinary incontinence was $5.48 \pm 6.84$ years (in the range of 1-8 years). The median vesical leak point pressure was $140 \mathrm{~cm} \mathrm{H}_{2} \mathrm{O}$ (range: 115 to 231), the postvoid residual was $28 \mathrm{cc}$ (range: 10-40) and the bladder capacity was $303 \mathrm{cc}$ (range: 184-469).

Before being discharged, all 28 patients voided spontaneously in the recovery room. The mean postprocedure VAS pain score was $2.7 \pm 0.9$ (range: $2-4$ ). Treatment procedures were well tolerated by all patients and no notable adverse events were detected. No voiding pattern changes or voiding difficulties were reported by the patients. Just one participant indicated an unexpected burning sensation of the anterior vaginal wall just after the procedure.

Assessing patients' satisfaction at 12 months revealed that $61 \%$ of the patients were extremely satisfied, $24 \%$ were satisfied, and $15 \%$ were neutral with the treatment based on their answer to the Likert-scale questionnaire.

The baseline mean I-QOL total score for all 28 subjects was $48.46 \pm 4.10$. Significant changes were observed in the mean I-QOL total score and pad test (Table 1). Furthermore, a notable reduction was observed in the number of daily leakage episodes and the Q-tip test on any follow-up visit $(P=0.001)$.

Resting to cough Q-tip excursion was 42 degrees prior to surgery compared with 27 degrees at 12 months $(P<0.001)$. On each follow-up visit, leakage episodes were assessed using 7-day voiding diaries. Comparing the baseline with 12-month observations showed that 21 patients manifested reduced episodes and seven had an unchanged number of leaking episodes.

\section{Discussion}

There are several treatment options available for patients with symptomatic SUI. ${ }^{18} \mathrm{RF}$ is one of the recent novel modalities in treating SUI. Due to rapid outcomes, noninvasiveness and absence of adverse effects, it has gained significant popularity in recent years. ${ }^{19}$ $\mathrm{RF}$ generates heat which stimulates the tissue matrix (consisting of elastin, collagen and ground substances) that ultimately results in an instant alteration of collagen's helical structure. Furthermore, owing to microinflammatory stimulation of fibroblasts, neoelastogenesis and neocollagenesis processes are activated, ${ }^{20,21}$ leading to the shrinkage of the treated tissue in the healing phase. The tightening caused by this shrinkage results in improved bladder neck stabilization, which ultimately leads to continence being restored. ${ }^{12}$ The collagen remodeling process, which can take up to 90 days, results in treatment outcome improvement. ${ }^{19}$

This pilot study was carried out to assess the efficacy and safety of TV-RF treatment in patients' quality of life and the frequency of incontinence episodes in women with SUI. At 6 months, all subjects showed an IEF (incontinence episode frequency) reduction and also an improvement in the I-QOL total score. There were no complications. No one suffered from voiding dysfunction. Moreover, there were no considerable changes in the anterior vaginal wall prolapse incidence.

Similar to the study by Millheiser et al, in which RF (frequency of $75-90 \mathrm{~J} / \mathrm{cm}^{2}$ ) was used for the treatment of vaginal laxity, this study showed that there was no adverse effect for similar procedures. ${ }^{22}$

Treating SUI based on the denaturation of collagen is a relatively novel concept. In a study by Appell et al, the results of 21 subjects who underwent RF were reported. They had follow-up sessions after 3 years based on 3-day diaries. Diaries were investigated to detect subjects with $50 \%$ or more reduction in IEF compared with the baseline. For 21 subjects who did not receive additional SUI intervention, changes in the I-QOL total score from the baseline were evaluated. The mean baseline score of I-QOL was $56.3 \pm 24$.6. Follow-up evaluation at 3 years revealed a mean improvement of $12.7 \pm 26.0$ (range: -26.14 to $62.5 ; P=0.04) .{ }^{23}$

In a study by Dmochowski et al, ${ }^{14}$ transvaginal RF was applied to 120 subjects. They reported that this approach had the efficacy and safety of laparoscopic procedures. No significant intra- or postoperative adverse events were reported in any of these studies.

Even though no randomized control trials are available, RF seems to be a convenient first-line therapy which is best suited for patients seeking an improvement in

Table 1. Comparison of I-QOL, Pad Test, Daily Leakage Episodes and Q-Tip Test on Different Visits

\begin{tabular}{|c|c|c|c|c|c|}
\hline Variable & Pretreatment & 1 Month & 6 Months & 12 Months & $P$ Value \\
\hline I-QOL & $48.46 \pm 4.10$ & $61.17 \pm 3.78$ & $70.27 \pm 2.88$ & $61.96 \pm 2.98$ & \\
\hline Pad test & & & & & 0.001 \\
\hline Mild & $2(7.1 \%)$ & $9(32.1 \%)$ & $15(53.6 \%)$ & $9(26.5 \%)$ & \\
\hline Moderate & $8(28.6 \%)$ & $10(35.7 \%)$ & $10(35.7 \%)$ & $15(44.1 \%)$ & \\
\hline Severe & $18(64.3 \%)$ & $9(32.1 \%)$ & $3(10.7 \%)$ & $10(29.4 \%)$ & \\
\hline $\begin{array}{l}\text { Daily leakage } \\
\text { episodes }\end{array}$ & $2.92 \pm 0.60$ & $1.35 \pm 0.78$ & $1.03 \pm 0.42$ & $1.25 \pm 0.44$ & \\
\hline Q-tip test & & & & & 0.000 \\
\hline+ & $27(96.4 \%)$ & $13(46.4 \%)$ & $5(17.9 \%)$ & $12(42.9 \%)$ & \\
\hline- & $1(3.6 \%)$ & $15(53.6 \%)$ & $23(82.1 \%)$ & $16(57.1 \%)$ & \\
\hline
\end{tabular}


their quality of life through nonsurgical therapy having repeated treatment potential.

\section{Conclusion}

Our preliminary results suggest that TV-RF is a safe and satisfactory treatment modality for SUI; also, we pointed out its low risk of adverse events. Significant changes were observed in the mean I-QOL total score and the pad test. Also, a notable reduction was observed in the number of daily leakage episodes.

However, there were several limitations to this pilot study, which are worth noting, including the possibility of repeated treatment and a small number of subjects as well as the lack of a control group. To increase the validity of the study, larger clinical trials with long-term follow-up are necessary.

\section{Ethical Considerations}

The study was approved by the Institutional Review Board (code: IR.SBMU.REC.1396.111). All patients were given counseling for appropriate informed consent before entering the study. All patients were treated by the same group of physicians.

\section{Conflict of Interests}

The authors declare that they have no conflict of interest.

\section{References}

1. Dillon B, Dmochowski R. Radiofrequency for the treatment of stress urinary incontinence in women. Curr Urol Rep. 2009;10(5):369-74. doi: 10.1007/s11934-009-0058-z.

2. Barbosa LMA, Lós DB, Silva IBd, Anselmo CW. The effectiveness of biofeedback in treatment of women with stress urinary incontinence: a systematic review. Rev Bras Saude Mater Infant. 2011;11(3):217-25.doi: 10.1590/S151938292011000300002

3. Norton P, Brubaker L. Urinary incontinence in women. Lancet. $\quad$ 2006;367(9504):57-67. doi:10.1016/S01406736(06)67925-7

4. Crivellaro S, Smith JJ. Minimally invasive therapies for female stress urinary incontinence: the current status of bioinjectables/new devices (adjustable continence therapy, urethral submucosal collagen denaturation by radiofrequency). Scientific World Journal. 2009;9:466-478. doi:10.1100/tsw.2009.53

5. Sand PK, Owens GM, Black EJ, Anderson LH, Martinson MS. Cost effectiveness of radiofrequency microremodeling for stress urinary incontinence. Int Urogynecol J. 2014;25(4):517-523. doi:10.1007/s00192-013-2230-8.

6. Buchsbaum GM, McConville J, Korni R, Duecy EE. Outcome of transvaginal radiofrequency for treatment of women with stress urinary incontinence. Int Urogynecol J Pelvic Floor Dysfunct. 2007;18(3):263-265. doi:10.1007/ s00192-006-0136-4

7. Razzaghi MR, Karkan MF, Ghiasy S, Javanmard B. Laser application in iran urology: a narrative review. J Lasers Med
Sci. 2018;9(1):1-6. doi:10.15171/jlms.2018.01

8. Leach GE, Dmochowski RR, Appell R, Blaivas JG, Hadley $\mathrm{HR}$, Luber KM, et al. Female stress urinary incontinence clinical guidelines panel summary report on surgical management of female stress urinary incontinence. $J$ Urol. 1997;158(3 Pt 1):875-880. doi:10.1097/00005392199709000-00054

9. Lordelo P, Boas AV, Sodré D, Lemos A, Tozetto S, Brasil C. New concept for treating female stress urinary incontinence with radiofrequency. Int Braz J Urol. 2017;43(5):896-902. doi:10.1590/S1677-5538.IBJU.2016.0621

10. Dmochowski R, Appell RA. Advancements in minimally invasive treatments for female stress urinary incontinence: radiofrequency and bulking agents. Curr Urol Rep. 2003;4(5):350-355. doi:10.1007/s11934-003-0005-3

11. Sotomayor M, Bernal GF. Twelve-month results of nonsurgical radiofrequency energy micro-remodeling for stress incontinence. Int Urogynecol J Pelvic Floor Dysfunct. 2005;16(3):192-196. doi:10.1007/s00192-004-1223-z

12. Ross JW, Galen DI, Abbott K, Albala D, Presthus J, Su-Ou $\mathrm{C}$, et al. A prospective multisite study of radiofrequency bipolar energy for treatment of genuine stress incontinence. J Am Assoc Gynecol Laparosc. 2002;9(4):493-499. doi:10.1016/s1074-3804(05)60525-7

13. Ismail SI. Radiofrequency remodelling of the endopelvic fascia is not an effective procedure for urodynamic stress incontinence in women. Int Urogynecol J Pelvic Floor Dysfunct. 2008;19(9):1205-1209. doi:10.1007/s00192-0080620-0

14. Dmochowski RR, Avon M, Ross J, Cooper JM, Kaplan $\mathrm{R}$, Love $\mathrm{B}$, et al. Transvaginal radio frequency treatment of the endopelvic fascia: a prospective evaluation for the treatment of genuine stress urinary incontinence. J Urol. 2003;169(3):1028-1032. doi:10.1097/01. ju.0000048686.50716.ef

15. Nojomi M, Baharvand P, Patrick DL. Incontinence quality of life questionnaire (I-QOL): translation and validation study of the Iranian version. Int Urogynecol J Pelvic Floor Dysfunct. 2009;20(5):575-579. doi:10.1007/s00192-0090808-y

16. Lenihan Jr JP. Comparison of the quality of life after nonsurgical radiofrequency energy tissue microremodeling in premenopausal and postmenopausal women with moderate-to-severe stress urinary incontinence. Am J Obstet Gynecol. 2005;192(6):1995-2001. doi:10.1016/j. ajog.2005.02.041

17. Appell RA, Juma S, Wells WG, Lenihan JP, Klimberg IW, Kanellos A, et al. Transurethral radiofrequency energy collagen micro-remodeling for the treatment of female stress urinary incontinence. Neurourol Urodyn. 2006;25(4):331-336. doi:10.1002/nau.20185

18. Rovner ES, Wein AJ. Treatment options for stress urinary incontinence. Rev Urol. 2004;6 Suppl 3(Suppl 3):S29-S47.

19. Lalji S, Lozanova P. Evaluation of the safety and efficacy of a monopolar nonablative radiofrequency device for 
the improvement of vulvo-vaginal laxity and urinary incontinence. J Cosmet Dermatol. 2017 Jun;16(2):230-234. doi: 10.1111 /jocd.12348.

20. Simopoulos TT, Nagda J, Aner MM. Percutaneous radiofrequency lesioning of the suprascapular nerve for the management of chronic shoulder pain: a case series. J Pain Res. 2012;5:91-97. doi:10.2147/JPR.S29864

21. Malerich SA, Nassar AH, Dorizas AS, Sadick NS. Radiofrequency: an update on latest innovations. J Drugs Dermatol. 2014;13(11):1331-1335.
22. MillheiserLS, PaulsRN, HerbstSJ, Chen BH.Radiofrequency treatment of vaginal laxity after vaginal delivery: nonsurgical vaginal tightening. J Sex Med. 2010;7(9):30883095. doi:10.1111/j.1743-6109.2010.01910.x

23. Appell RA, Singh G, Klimberg IW, Graham C, Juma S, Wells WG, et al. Nonsurgical, radiofrequency collagen denaturation for stress urinary incontinence: retrospective 3-year evaluation. Expert Rev Med Devices. 2007;4(4):455461. doi:10.1586/17434440.4.4.455 